\title{
QbD-Oriented Development and Characterization of Effervescent Floating-Bioadhesive Tablets of Cefuroxime Axetil
}

\author{
Sanjay Bansal, ${ }^{1,2}$ Sarwar Beg, ${ }^{3}$ Babita Garg, ${ }^{3}$ Abhay Asthana, ${ }^{1,4}$ Gyati S. Asthana, ${ }^{1}$ and Bhupinder Singh ${ }^{3,4}$
}

Received 2 August 2015; accepted 7 October 2015; published online 2 November 2015

\begin{abstract}
The objective of the present studies was systematic development of floating-bioadhesive gastroretentive tablets of cefuroxime axetil employing rational blend of hydrophilic polymers for attaining controlled release drug delivery. As per the QbD-based approach, the patient-centric target product profile and quality attributes of tablet were earmarked, and preliminary studies were conducted for screening the suitability of type of polymers, polymer ratio, granulation technique, and granulation time for formulation of tablets. A face-centered cubic design (FCCD) was employed for optimization of the critical material attributes, i.e., concentration of release controlling polymers, PEO 303 and HPMC K100 LV CR, and evaluating in vitro buoyancy, drug release, and ex vivo mucoadhesion strength. The optimized formulation was embarked upon through numerical optimization, which yield excellent floatation characteristic with drug release control (i.e., $T_{60 \%}>6 \mathrm{~h}$ ) and bioadhesion strength. Drug-excipient compatibility studies through FTIR and P-XRD revealed the absence of any interaction between the drug and polymers. In vivo evaluation of the gastroretentive characteristics through $\mathrm{X}$-ray imaging and in vivo pharmacokinetic studies in rabbits revealed significant extension in the rate of drug absorption (i.e., $T_{\max }$, $K_{\mathrm{a}}$, and MRT) from the optimized tablet formulation as compared to the marketed formulation. Successful establishment of various levels of in vitro/in vivo correlations (IVIVC) substantiated high degree of prognostic ability of in vitro dissolution conditions in predicting the in vivo performance. In a nutshell, the studies demonstrate successful development of the once-a-day gastroretentive formulations of cefuroxime axetil with controlled drug release profile and improved compliance.
\end{abstract}

KEY WORDS: drug release; gastroretentive; mucoadhesion; quality by design; $x$-ray imaging.

\section{INTRODUCTION}

Oral intake is considered as the most preferable route of drug delivery owing to the ease of administration, patient compliance, and flexibility in formulation development. In this regard, oral controlled release (CR) formulations are primarily employed for reducing the frequency of administration by regulating the drug release rate for prolonged periods of time, thus improving the patient compliance $(1,2)$. However, development of CR products is precluded by their inability to retain the formulation within the desired region of gastrointestinal

Electronic supplementary material The online version of this article (doi:10.1208/s12249-015-0431-9) contains supplementary material, which is available to authorized users.

\footnotetext{
${ }^{1}$ Maharishi Markandeshwar College of Pharmacy, Maharishi Markandeshwar University, Mullana, Ambala, Haryana 133 207, India.

${ }^{2}$ Department of Pharmacy, MCP College, Jalandhar City, Punjab 144 008, India.

${ }^{3}$ University Institute of Pharmaceutical Sciences, UGC Centre of Advanced Studies, UGC Center for Excellence in Nano Applications, Panjab University, Chandigarh, 160 014, India.

${ }^{4}$ To whom correspondence should be addressed. (e-mail: abhaypharmacy@gmail.com, bsbhoop@yahoo.com)
}

tract (GIT), invariably resulting in incomplete drug absorption, and submaximal therapeutic response (3).

Gastroretentive drug delivery systems (GRDDS) complement the oral $\mathrm{CR}$ formulations by providing continuous drug release for prolonged periods of time through the "absorption window" ensuring optimal extent of bioavailability (3-5). In the past few decades, several literatures have been reported on the development of GRDDS including bioadhesive systems, density controlled systems, and size expanding systems. Among these, the density controlled systems hold promising potential to improve the gastric residence time of the drugs. The vital ones include the low-density effervescent and non-effervescent floating systems, swelling and expanding systems, and raft-forming systems (6). With a bulk density less than that of gastric fluid, floating system remains buoyant in the stomach for a prolonged periods of time without reducing the gastric emptying rate and offers better control over the fluctuations in plasma drug levels (7).

The floating systems, however, possess multiple challenges like insufficient floatation when the fluid level is low in the stomach and chances of transit of the dosage form to the pylorus by forcible house-keeping waves, leading eventually to reduced buoyancy time and limited retention of the dosage form. These limitations can largely be overcome by developing the floating systems coupled with mucoadhesion 
characteristics to adhere the dosage form to the mucous lining of stomach wall $(1,8)$. The floating-bioadhesive systems therefore greatly improve the residence time of the drug resulting in effective extension in the absorption and oral bioavailability.

Cefuroxime axetil is a prodrug, belongs to the second-generation cephalosporin and shows broad spectrum action against gram-negative and gram-positive bacteria. It shows site-specific absorption in the proximal region of GIT owing to its weekly acidic nature (9). However, after oral administration, it undergoes metabolism in the presence of esterase to its non-absorbable form, cefuroxime, which primarily exhibits low and inconsistent oral bioavailability (i.e., <40\%) $(10,11)$. Besides, predisposition of the linear saturation kinetic behavior of the cefuroxime axetil is known to be responsible for its reduced plasma concentration (12). The conventional immediate release (IR) formulation available in the market shows inability to accomplish desired drug release profile owing to poor retentivity in the stomach for extended periods of time. Although literature reports have demonstrated the utility of diverse GR floating formulations of cefuroxime axetil, yet, these systems are not considered to be highly satisfactory for attaining the desired retentivity in the gastric absorption window owing to floatation characteristics only (13-18). Thus, attempts were made to develop the GR tablets employing dual approach of floatation and bioadhesion for maintaining drug absorption and plasma concentration of the drug for prolonged periods of time and improving the therapeutic efficacy of cefuroxime axetil.

Development of GR systems primarily involve multiple intricacies involving selection of suitable rate controlling polymers, their apt concentrations, granulation technique, compression force, etc (19), for attaining maximal therapeutic benefits. Optimizing the formulation composition and the manufacturing process(es) of such systems using traditional one-factor-at-a-time (OFAT) is considered to be a herculean task with expenditure of a great deal of time, money, and effort to produce just workable solutions $(20,21)$. In this context, systematic development of drug products employing Quality by Design (QbD) paradigms has been lately popular for comprehensive understanding of the diverse formulation systems. Based on the principles of Quality Risk Management (QRM) and Design of Experiments (DoE), QbD approach provides "the best" possible solutions by furnishing product and/or process understanding (22-24).

The present research work, therefore, conducted for QbD-based development of GR floating-bioadhesive tablets of cefuroxime axetil employing optimized polymer blends, i.e., PEO 303 and HPMC K100 LV CR as the mucoadhesive and release controlling polymers. The prepared formulations were subsequently evaluated for in vitro floating time, drug release, ex vivo bioadhesion strength, in vivo GR nature through X-ray imaging, and pharmacokinetic studies in rabbits. Also, the prepared formulations were investigated for the plausibility of correlation between the in vivo \%drug absorbed data with the in vitro \%drug release absorbed data from the optimized formulation.

\section{MATERIALS AND METHODS}

\section{Materials}

Cefuroxime axetil, HPMC K4M CR, K15M CR, and K100 LV CR were provided ex gratis by M/s Ranbaxy Laboratories Ltd., Gurgaon, India. PEO 303, N-80, and coagulant grade were obtained as gift samples from M/s Colorcon Asia Ltd., Goa, India, while sodium bicarbonate and magnesium stearate were received from M/s Loba Chemie Ltd., Mumbai, India. Porcine gastric mucosa employed for determining the bioadhesive strength was obtained from abattoir in the suburbs of Chandigarh, India. All other chemicals and reagents used were of analytical reagent grade and were used as received.

\section{Methods}

\section{Defining the QTPP and CQAs}

As per the QbD-based approach of drug product development, the quality target product profile (QTPP) was defined encompassing the summary of quality characteristics of the drug product for accomplishing the desired GR drug delivery for attaining maximal therapeutic benefits. In order to meet the QTPP, various patient-centric critical quality attributes (CQAs) pertaining to the quality of finished product were defined. Supplementary data Table 1 summarizes the key elements of QTPP for preparing the GR floatingbioadhesive tablets, while Supplementary data Table 2 enlists the CQAs along with apt justifications for them.

\section{Screening of Polymers}

Six polymers viz. HPMC K4M CR, HPMC K15M CR, HPMC K100 LV CR, PEO 303, PEO N-80, and PEO coagulant grade were chosen at different ratios for formulating the gastroretentive floating-bioadhesive tablets. Further, the prepared formulations were evaluated for in vitro floating time, drug release parameters, and bioadhesion strength for identifying the suitable polymer combination for the purpose.

\section{Drug-Excipient Compatibility Studies}

Fourier Transform Infrared (FT-IR) Spectroscopy. The Fourier transform infrared (FT-IR) spectroscopy was performed to characterize the possible interactions between the drug and excipients, if any. The FT-IR spectra of drug and polymer mixture were recorded in $\mathrm{KBr}$ disc over the range $4000-450 \mathrm{~cm}^{-1}$ using an FT-IR spectrophotometer (M/s Perkin Elmer, Massachusetts, USA).

Powder X-Ray Diffraction (P-XRD). The powder X-ray diffraction (P-XRD) studies were carried out for solid-state characterization of the drug, polymers, and their physical mixtures. The diffraction pattern of samples was recorded by X-ray diffractometer, Philips PW 17291 (M/s Philips Instruments, DA Best, The Netherlands) using Ni-filtered, $\mathrm{Cu} \mathrm{kV}$ radiation, at a voltage of $40 \mathrm{kV}$. The P-XRD spectra, thus obtained, were compared for identifying physiochemical incompatibility, if any. 
Table I. Composition of Floating-Bioadhesive Tablets of Cefuroxime Axetil

\begin{tabular}{ll}
\hline Ingredient & Amount (mg) \\
\hline Cefuroxime axetil & 300 \\
PEO 303 & $30-50$ \\
HPMC K100 LV CR & $40-120$ \\
Sodium bicarbonate & 66 \\
Magnesium stearate & 5.5 \\
Lactose & q.s. \\
\hline
\end{tabular}

q.s. quantity sufficient

Preparation of Floating-Bioadhesive Tablets as per the Experimental Design. The floating-bioadhesive tablets of cefuroxime axetil were prepared by direct compression employing different ratios of polymers (i.e., PEO 303 and HPMC K100 LV CR). The detail composition of the prototype formulation employed during the study has been enlisted in Table I. A total of 13 formulations were prepared as per the face-centered cubic design (FCCD) with $\alpha=1$, by selecting aforesaid factors as the CMAs including quintuplicate studies at the center point $(0,0)$, while keeping the amount of sodium bicarbonate and magnesium stearate as constant at $12 \% \mathrm{w} / \mathrm{w}$ and $1 \% w / w$ of the total tablet weight, respectively (Table II). Lactose was added as a filler to maintain constant tablet weight, i.e., $550 \mathrm{mg}$. For preparing the tablets, cefuroxime axetil, lactose, and the polymers, viz. PEO 303 and HPMC K100 LV CR were screened through \#40 mesh sieve, and magnesium stearate was screened through \#80 mesh sieve. All the materials except magnesium stearate were mixed intimately for $10 \mathrm{~min}$. Then the blended mix was lubricated with magnesium stearate for $2 \mathrm{~min}$. Finally, the lubricated mix was compressed into $550 \mathrm{mg}$ tablets using flat faced round punches (11-mm diameter) fitted to a single-punch tablet compression machine (M/s Cadmach, Ahmedabad, India). The prepared formulations were evaluated for CQAs viz. bioadhesion strength (BS), amount of drug released in $18 \mathrm{~h}\left(Q_{18 \mathrm{~h}}\right)$, time

Table II. Design Matrix for Preparing the Gastroretentive FloatingBioadhesive Tablets of Cefuroxime Axetil

\begin{tabular}{llll}
\hline Formulation code & Experimental & \multicolumn{2}{c}{ Coded factor levels } \\
& trial no. & $X_{1}$ & $X_{2}$ \\
F1 & 1 & -1 & -1 \\
F2 & 2 & -1 & 0 \\
F3 & 3 & -1 & 1 \\
F4 & 4 & 0 & -1 \\
F5 & 5 & 0 & 0 \\
F6 & 6 & 0 & 1 \\
F7 & 7 & 1 & -1 \\
F8 & 8 & 1 & 0 \\
F9 & 9 & 1 & 1 \\
Translation of coded levels in actual units & & \\
& Low & Intermediate & High \\
Coded levels & -1 & 0 & 1 \\
$X_{1}:$ HPMC K100 LV & 40 & 80 & 120 \\
CR (mg) & & & \\
$X_{2}$ : PEO 303 (mg) & 30 & 40 & 50 \\
\hline
\end{tabular}

*Center point formulation studied at quintuplicate times taken for $60 \%$ drug release $\left(T_{60 \%}\right)$, and $\mathrm{n}$ (drug release exponent).

\section{Characterization of the floating-bioadhesive tablets}

\section{Tablet assay and physical evaluation}

Ten tablets were pulverized together, and quantity of powder equivalent to $20 \mathrm{mg}$ of cefuroxime axetil was shaken with $60 \mathrm{~mL}$ of methanol for $10 \mathrm{~min}$. The resulting suspension was heated at $60^{\circ} \mathrm{C}$ and shaken for $15 \mathrm{~min}$. The contents were allowed to cool and diluted with $100 \mathrm{~mL}$ methanol and filtered through Whatman ${ }^{\circledR}$ grade 597 filter paper (M/s Whatman International Ltd., Kent, UK). The samples were analyzed spectrophotometrically at a $\lambda_{\max }$ of $281 \mathrm{~nm}$, and the content of cefuroxime axetil was determined using a previously constructed linear calibration plot. The prepared tablets were also evaluated for hardness using an electronic hardness tester (EH-01P, M/s Electrolab Instruments, Mumbai, India, $n=6$ ), thickness using Vernier Calliper (M/s Baker Gauges Ltd., Pune, India, $n=10)$, friability using Roche's friabilator (M/s Tropical Lab Equipment, Mumbai, India, $n=6$ ), and weight variation using Analytical balance (AE 240, M/s Mettler Toledo, Greifensee, Switzerland, $n=10)$.

\section{In vitro floating studies}

The floating characteristics of the prepared floatingbioadhesive tablets were determined from the in vitro floating studies performed in simulated gastric fluid (SGF, pH 1.2) without pepsin. These tablets were transferred to the dissolution medium taken in USP Type II dissolution apparatus kept at $50 \mathrm{rpm}$ and $37 \pm 0.5^{\circ} \mathrm{C}$. The time required for onset of floatation and duration of floating was observed during the $24 \mathrm{~h}$ dissolution run.

\section{In vitro drug release studies}

In vitro drug release studies of floating-bioadhesive tablets containing cefuroxime axetil were conducted in hexaplicate employing USP Type II apparatus at 37 $\pm 0.5^{\circ} \mathrm{C}$ and $50 \pm 0.5 \mathrm{rpm}$ employing $900 \mathrm{~mL}$ of simulated gastric fluid (SGF) of $\mathrm{pH} 1.2$ without enzymes as dissolution medium. Aliquot of $(5 \mathrm{~mL})$ sample was withdrawn periodically at suitable time intervals followed by replenishment with equal volume of plain dissolution medium. The withdrawn samples were filtered, diluted suitably, and analyzed spectrophotometrically at $281 \mathrm{~nm}$ employing a UV-visible spectrophotometer $3000^{+}$(M/s Labindia Instruments Pvt. Ltd., Mumbai, India). The release data were analyzed using ZOREL software having in-built provisions for compensating the loss in volume and drug during sampling using Eq. (1) mentioned below $(25,26)$.

$C_{\mathrm{i}}=A_{\mathrm{i}} \frac{V_{\mathrm{s}}}{V_{\mathrm{t}}} \times \sum_{i=1}^{n-1} A_{\mathrm{i}}\left[\frac{V_{\mathrm{t}}}{V_{\mathrm{s}}-V_{\mathrm{t}}}\right]$

where $C_{\mathrm{i}}$ is the corrected absorbance; $A_{\mathrm{i}}$ is the absorbance of $i^{\text {th }}$ reading; $V_{\mathrm{s}}$ is the sample volume; and $V_{\mathrm{t}}$ is the total volume of dissolution medium.

The amount of drug dissolved, percent release, rate of drug release, and $\log$ fraction released at varied times were also evaluated (26). The time taken for $60 \%$ of drug release $\left(T_{60 \%}\right)$ was computed using Stineman interpolation of Micromath software (M/s Micromath Inc., Missouri, USA). Drug release data were fitted into Korsemeyer-Peppas model 
for swellable matrices, as per the Eq. (2) mentioned below (27).

$\frac{M_{\mathrm{t}}}{M_{\infty}}=k_{1} \cdot t^{n}+k_{2} \cdot t^{2 n}$

where $M_{\mathrm{t}}$ is the amount of drug released at time ' $t$ ', $M_{\infty}$ is the amount of drug released at an infinite time. ' $n$ ' represents the values of release exponent indicating the kinetics of drug release, ' $k$ ' indicates kinetic constant, and $k_{1}$ and $k_{2}$ stand for the magnitude of Fickian diffusion and polymer relaxation, respectively.

Ex Vivo Bioadhesion Studies. Ex vivo bioadhesion strength of the prepared formulations was carried out by Texture Profile Analyzer (TAX TEE 32, M/s Stable Microsystems, Godalming Surrey, UK). Porcine gastric mucosa was used as model membrane to determine bioadhesive strength. The mucosal membrane was excised by removing the underlying connective tissue and placed on the base of texture analyzer, where a tablet was attached to the stainless-steel probe of the mobile arm. Prior to the experiment, the area of contact of mucosa with tablet surface was moistened with $50 \mu \mathrm{L}$ of SGF. The mobile arm was lowered at a rate of $0.5 \mathrm{~mm} / \mathrm{s}$ until a contact with the membrane. A contact force of $10 \mathrm{~g}$ was maintained for $300 \mathrm{~s}$, after which the probe was withdrawn from the membrane. Bioadhesion strength was determined in terms of force required to detach the tablet from the membrane.

Optimization Data Analysis and Validation of $Q b D$ Methodology. The QbD optimization data analysis was carried out after evaluating prepared tablets for various CQAs like BS, $Q_{18 \mathrm{~h}}, T_{60 \%}$, and $n$. Mathematical modeling was conducted by multiple linear regression analysis followed by polynomial analysis using second-order quadratic model to explore the plausibility of significant interaction(s) among the CMAs. Only the coefficients found to be significant corresponding to each model terms were considered during framing the polynomial equation(s). The aptness of selected model was carried out by analyzing the model parameters like $p$ value, coefficient of correlation $(r)$, and lack of fit analysis. The prognosis of optimum formulation was conducted by brute force technique in two stages, i.e., a feasible search and exhaustive grid search. The criterion adopted for feasibility search was:

$B S>\mathbf{2 0} \mathbf{g} ; T_{60 \%}>\mathbf{6 . 0} \mathbf{h} ; Q_{18 h}>\mathbf{8 0} \% ; \mathbf{n}>\mathbf{0 . 6}$

After feasibility search, a desired region was selected and subsequently explored for identifying the suitable optimal region by grid search analysis. The more stringent criterion adopted for exhaustive grid search enumerated as follows:

$B S>20 \mathrm{~g} ; T_{60 \%}>\mathbf{7 . 0} \mathbf{h} ; Q_{18 h}>\mathbf{9 0} \% ; \mathbf{n}>\mathbf{0 . 6 6}$

The optimized formulation was also located by numerical optimization and desirability function while "trading-off" of the CQAs, as per the aforementioned criterion for grid search and located in the optimal design space region.

Validation of QbD methodology was carried out by preparing seven formulations as the confirmatory check points. The observed and predicted responses were critically compared by constructing the linear correlation plots. The residual analysis was also performed by calculating the percent bias (i.e., percent prediction error) from the predicted and observed values of the responses.

Comparison of Drug Release Performance with Marketed Brand. Drug release profile of the optimized formulation was compared with the marketed formulation (Pulmocef $\AA$; M/s Microlab Ltd, Bangalore, India), as per the procedure stated for in vitro drug release studies. The marketed brand was the immediate release formulation, which was selected owing to the unavailability of controlled release product in the market.

In Vivo X-ray Imaging Studies. In vivo animal studies was performed using X-ray imaging technique for evaluating the GR potential of the optimized tablet formulation as per the protocol approved by the Institutional Ethical Committee, Maharishi Markandeshwar University, Mullana, Ambala, India. Unisex rabbits (weighing 2-2.5 kg) were housed under standard laboratory conditions at $25 \pm 2{ }^{\mathrm{O}} \mathrm{C}$ and $55 \pm 5 \% \mathrm{RH}$ with standard diet and tap water ad libitum. Prior to initiation of the studies, the animals were kept overnight under fasting condition in order to avoid difficulties during imaging. X-ray image of the empty stomach was taken in animals prior to experimentation. The animals were orally administered with the optimized tablet formulation and marketed formulation containing cefuroxime axetil equivalent to $300 \mathrm{mg} / \mathrm{kg}$ body weight of rabbit. The animals were placed in the upright position for imaging to locate the position of both control and floating-bioadhesive tablets in the GI tract under X-ray machine (M/s Siemens 300 MA with fluoroscopy, München, Germany) at different time intervals like $0.5,2,4,6$, and $12 \mathrm{~h}$, respectively.

In Vivo Pharmacokinetic Studies. A single-dose parallel design study was carried out using New Zealand male rabbits with body weights ranging between 1.82 and $2.57 \mathrm{~kg}$, and aged between 2 and 3 years. Taking cognizance that the research work adheres to the guidelines for care and use of the laboratory animals, all the animal investigations were performed as per the requisite protocol approved by the Institutional Animal Ethic Committee of Maharishi Markhandeswar University, Ambala, India.

The study involved two groups (A and B) with three rabbits being randomly distributed in each group. Prior to dose administration, rabbits were fasted overnight in the restraining cages to prevent coprophagy. The animals were divided into the following two groups based on their dosing schedule:

Group A: peroral administration of marketed formulation (Pulmocef®) containing cefuroxime axetil equivalent to $300 \mathrm{mg} / \mathrm{kg}$ b.w of rabbits

Group B: peroral administration of optimized floatingbioadhesive tablet containing cefuroxime axetil equivalent to $300 \mathrm{mg} / \mathrm{kg}$ b.w of rabbits 
Table III. Various Parameters of the Gastroretentive Floating-Bioadhesive Tablet Formulations of Cefuroxime Axetil Containing in 2:1 Ratio of Drug: Polymers

\begin{tabular}{|c|c|c|c|c|c|c|c|c|c|}
\hline \multirow[t]{2}{*}{ Parameters } & \multicolumn{9}{|c|}{ Polymer combinations } \\
\hline & $\begin{array}{l}1 \\
\text { HPMC } \\
\text { K15 M } \\
\text { CR+ } \\
\text { PEO } \\
303\end{array}$ & $\begin{array}{l}2 \\
\text { HPMC } \\
\text { K15 M } \\
\text { CR+ } \\
\text { PEO } \\
\text { N-80 }\end{array}$ & $\begin{array}{l}3 \\
\text { HPMC } \\
\text { K15 M } \\
\text { CR+PEO } \\
\text { Coaggulant }\end{array}$ & $\begin{array}{l}4 \\
\text { HPMC } \\
\text { K4M } \\
\text { CR+ } \\
\text { PEO } \\
303\end{array}$ & $\begin{array}{l}5 \\
\text { HPMC } \\
\text { K4M } \\
\text { CR+ } \\
\text { PEO } \\
\text { N-80 }\end{array}$ & $\begin{array}{l}6 \\
\text { HPMC K4M } \\
\text { CR+PEO } \\
\text { Coaggulant }\end{array}$ & $\begin{array}{l}7 \\
\text { HPMC } \\
\text { K100LV } \\
\text { CR+ } \\
\text { PEO } 303\end{array}$ & $\begin{array}{l}8 \\
\text { HPMC } \\
\text { K100LV } \\
\text { CR+ } \\
\text { PEO } \\
\text { N-80 }\end{array}$ & $\begin{array}{l}9 \\
\text { HPMC } \\
\text { K100LV } \\
\text { CR+PEO } \\
\text { Coaggulant }\end{array}$ \\
\hline$T_{60 \%}(\mathrm{~h})$ & 24.34 & 22.12 & 27.54 & 16.53 & 14.89 & 17.56 & 7.45 & 24.5 & 20.78 \\
\hline$Q_{18 \mathrm{~h}}(\%)$ & 41.67 & 45.87 & 38.56 & 65.56 & 70.54 & 60.12 & 94.34 & 55.5 & 58.9 \\
\hline $\begin{array}{l}\text { Floating } \\
\text { time, } T_{\mathrm{b}}(\mathrm{h})\end{array}$ & 25.8 & 27.2 & 28.1 & 25.5 & 28.6 & 27.1 & 24.0 & 18.3 & 26.5 \\
\hline $\begin{array}{l}\text { Bioadhesive } \\
\text { strength, BS (g) }\end{array}$ & 16.2 & 12.3 & 11.4 & 16.1 & 11.5 & 12.2 & 28.1 & 11.5 & 12.4 \\
\hline
\end{tabular}

Following peroral administration, the rabbits were kept in cages, and access to food and water was provided ad libitum. Serial aliquots of blood samples (about $1.0 \mathrm{~mL}$ each) were withdrawn from the marginal ear vein at periodic time intervals of $0,1,2,3,4,6,8,10,12,18$, and $24 \mathrm{~h}$. Blood samples were placed in the heparinized tubes, and plasma was harvested by centrifugation at $10,000 \mathrm{rpm}(4528 \times \mathrm{g})$ for $10 \mathrm{~min}$. Plasma samples were stored at $-20^{\circ} \mathrm{C}$ till analyzed. To each $0.2 \mathrm{~mL}$ aliquot of plasma sample, $0.2 \mathrm{~mL}$ of acetonitrile was added to precipitate plasma proteins. The samples were subsequently centrifuged at $5000 \mathrm{rpm}(1398 \times g)$ for $5 \mathrm{~min}$, and the supernatant was injected into the liquid chromatographic system LC2231 CHT (M/s Waters Corporation, Massachusetts, USA), with C-18 column (M/s Merck KGaA, Germany) with dimension of $250 \times 4.6 \mathrm{~mm}, 5 \mu \mathrm{m}$ for the analysis of drug. The concentration of cefuroxime acid in plasma was determined using the previously developed and validated bioanalytical method. The solvent mixture containing $70 \mathrm{mM}$ phosphate buffer $(\mathrm{pH} 3.0)$ and acetonitrile (63:37 $v / v)$ was employed as the mobile phase, which was delivered at a flow rate of $0.8 \mathrm{~mL} \min ^{-1}$ and the detection wavelength of cefuroxime at $275 \mathrm{~nm}$. The injection volume was $10 \mu \mathrm{L}$, and analysis was performed at column oven temperature of $40^{\circ} \mathrm{C}$.

Pharmacokinetic analysis of the plasma drug concentration data was conducted employing a Win-Nonlin Ver. 5.0 (M/s Pharsight Corp, California, USA). Various pharmacokinetic parameters such as maximum observed plasma concentration $\left(C_{\max }\right)$ and the corresponding time $\left(T_{\max }\right)$, area under the curve $\left(A U C_{24 \mathrm{~h}}\right)$, absorption rate constant $\left(K_{\mathrm{a}}\right)$, and elimination rate constant $(K)$ were computed using the "Model 3 " for compartmental (i.e., one compartment), while mean residence time (MRT) calculated from the noncompartmental pharmacokinetic analysis. The statistical validity of the results was discerned on the basis of the minimization of various model fitness parameters like Akaike Information Criterion (AIC), Schwartz Criterion (SC), sum of squares due to residuals (SSR), and maximization of Pearsonian correlation coefficient (R). Also, the two-way ANOVA was performed using GarphPad Prism ver 6.01 (M/s GraphPad Software Inc., CA, USA) for statistical analysis of the plasma concentration-time data at $5 \%$ level of significance.

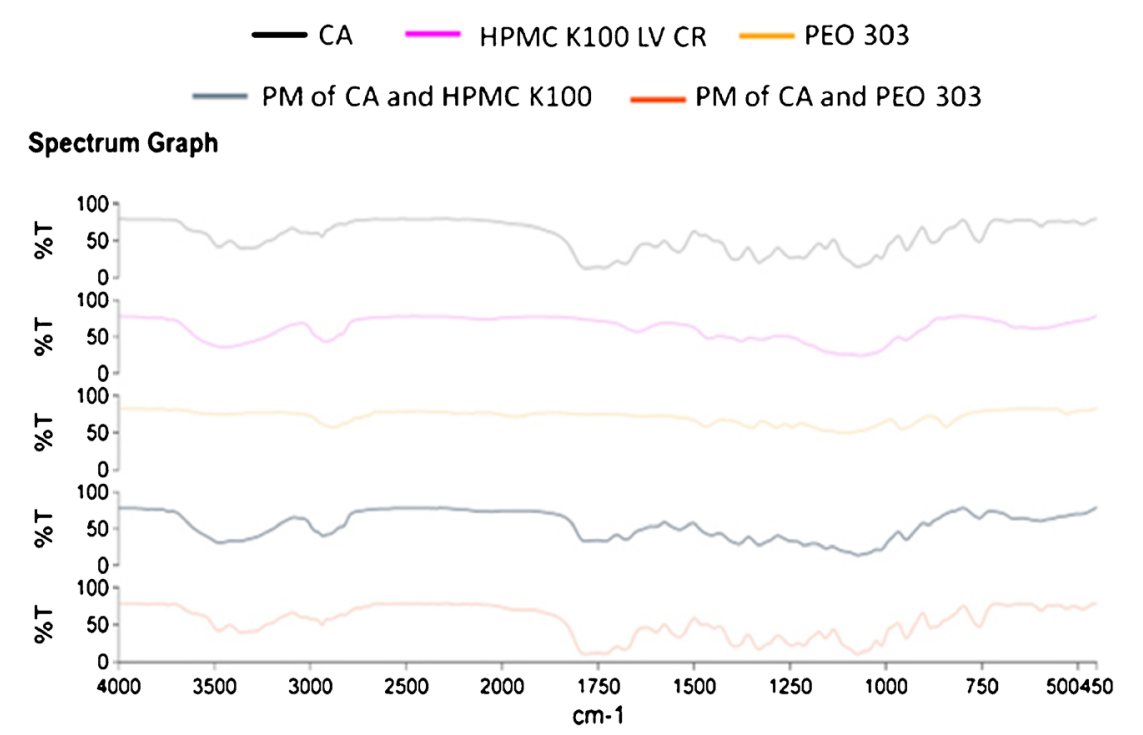

Fig. 1. FTIR spectrum of cefuroxime axetil, Methocel K100 LV CR, PEO 303, and their physical mixtures 


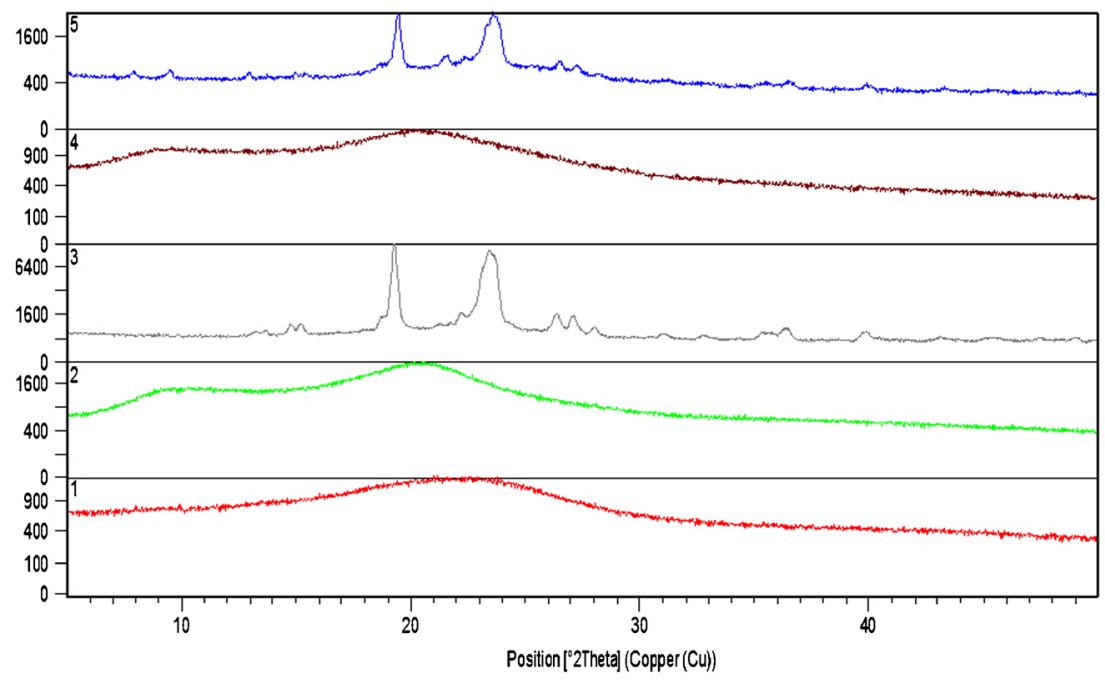

Fig. 2. P-XRD spectra of cefuroxime axetil (1), HPMC K 100 LV CR (2), PEO 303 (3), physical mixture of CA and HPMC K 100 LV CR (4), physical mixture of CA, and PEO $303(5)$

In Vitro/In Vivo Correlation (IVIVC). Level A correlations were attempted between the in vivo pharmacokinetic parameter and the in vitro dissolution parameter for optimized floating-bioadhesive tablet and the marketed immediate release tablet formulation. For exploring the Level A IVIVC, \%drug absorbed in vivo at various time points obtained using modified Wagner-Nelson method was correlated with \%drug release in vitro at the identical time points. The mathematical fitting of the data was carried out using linear and/or quadratic polynomial models to establish the relationship between the in vivo and in vitro data.

\section{RESULTS AND DISCUSSION}

\section{Selection of Polymers}

Table III enlists various characterization parameters like in vitro floating time, drug release parameters, and bioadhesion strength observed for nine polymer combinations studied employing 1:1 proportion of six polymer blends. The hardness of all the formulations was monitored to range between 5.2 and $6.1 \mathrm{~kg}$, with the value of friability observed to be less than $1 \% w / w$ for all the formulations. Out of the studied polymer combinations, the PEO 303 and HPMC K100 LV CR was found to be suitable on the basis of attainment of floating efficiency up to $24 \mathrm{~h}$ with no initial lag-time along with adequate bioadhesion strength and control of drug release parameters (i.e., $Q_{18 \mathrm{~h}}$ and $T_{60 \%}$ ).

\section{Drug-Excipient Compatibility Studies}

\section{Fourier Transform Infrared Spectroscopy (FT-IR)}

As portrayed in Fig. 1, the FT-IR spectra of cefuroxime axetil show major peak of N-H stretching at $3481 \mathrm{~cm}^{-1}$ and other characteristic absorption peaks at 1212, 1660, 1781, and $1734 \mathrm{~cm}^{-1}$ indicating the presence of carbonyl $\mathrm{C}=\mathrm{O}$ and $\mathrm{C}=\mathrm{H}$ stretching. Analogously, the physical mixture of drug with excipients viz. PEO 303 and HPMC K100 LV CR showed absence of any shifting in the wave numbers $\left(\mathrm{cm}^{-1}\right)$ of the

Table IV. Dissolution Parameters of Gastroretentive Floating-Bioadhesive Tablet Formulations of Cefuroxime Axetil as per Face-Centered Cubic Design

\begin{tabular}{|c|c|c|c|c|c|c|c|c|}
\hline \multirow[t]{2}{*}{ Code } & \multicolumn{2}{|c|}{ Formulation composition } & \multirow{2}{*}{$\begin{array}{l}\text { Release } \\
\text { exponent } \\
(n)\end{array}$} & \multirow{2}{*}{$\begin{array}{l}\text { Kinetic } \\
\text { Constant } \\
(K)\end{array}$} & \multirow{2}{*}{$\begin{array}{l}\text { Fickian } \\
\text { diffusion } \\
\left(k_{1}\right)\end{array}$} & \multirow{2}{*}{$\begin{array}{l}\text { Polymer } \\
\text { relaxation } \\
\left(k_{2}\right)\end{array}$} & \multirow{2}{*}{$\begin{array}{l}\text { Time taken to } \\
\text { release } 60 \% \\
\text { of drug }\left(T_{60 \%,} \mathrm{~h}\right)\end{array}$} & \multirow{2}{*}{$\begin{array}{l}\text { Drug released } \\
\text { till } 18 \mathrm{~h} \\
\left(Q_{18 \mathrm{~h}}, \%\right)\end{array}$} \\
\hline & HPMC (mg) & PEO303 (mg) & & & & & & \\
\hline $\mathrm{F} 1$ & 40 & 30 & 0.4711 & 0.2895 & 1.341 & 0.007 & 4.2 & 100.00 \\
\hline $\mathrm{F} 2$ & 40 & 40 & 0.5459 & 0.1965 & 1.1817 & 0.0324 & 7.0 & 94.40 \\
\hline F3 & 40 & 50 & 0.6146 & 0.1365 & 1.1092 & 0.0383 & 9.4 & 80.20 \\
\hline $\mathrm{F} 4$ & 80 & 30 & 0.5687 & 0.1737 & 1.1533 & 0.0351 & 7.5 & 90.45 \\
\hline F5 & 80 & 40 & 0.7609 & 0.0908 & 1.0351 & 0.0598 & 9.7 & 82.78 \\
\hline F6 & 80 & 50 & 0.7144 & 0.0851 & 1.0406 & 0.0458 & 14.1 & 69.54 \\
\hline F7 & 120 & 30 & 0.6622 & 0.1315 & 1.1109 & 0.0417 & 9.2 & 85.65 \\
\hline F8 & 120 & 40 & 0.8151 & 0.0566 & 1.0010 & 0.052 & 16.0 & 65.20 \\
\hline F9 & 120 & 50 & 0.9540 & 0.0404 & 0.9758 & 0.0611 & 16.1 & 66.18 \\
\hline
\end{tabular}




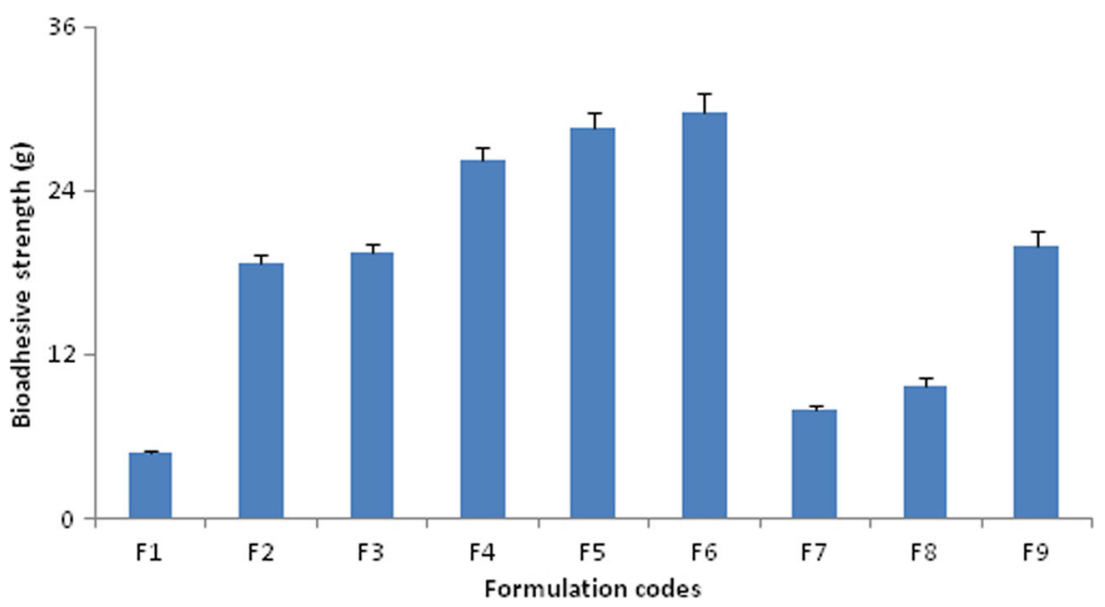

Fig. 3. Bioadhesive strengths of the formulations prepared as per the experimental design

drug, thus corroborate lack of physiochemical interaction(s) and incompatibility between the drug and polymers.

\section{Powder X-ray Diffraction Studies}

Figure 2 depicts the X-ray diffraction patterns of pure drug, PEO 303, HPMC K100 LV CR, and physical mixtures. $\mathrm{X}$-ray diffractograms of pure drug, HPMC and their physical mixture, exhibited amorphous characteristics with the absence of any sharp peaks, whereas PEO 303 and its physical mixture with pure drug exhibited sharp peaks by PEO owing to its crystalline nature. Overall, the studies confirmed the absence of any interaction(s) between the drug and polymers.

\section{Characterization of the Floating-Bioadhesive Tablets}

Tablet Assay and Physical Evaluation. The drug content of prepared tablets was varied between 99.12 and $100.2 \% \mathrm{w} / \mathrm{w}$ with mean \pm SD as $99.7 \pm 0.5 \%$. The evaluation of other parameters like tablet weight showed variation between 550.2 and $560.4 \mathrm{mg}(555.3 \pm 5.1 \mathrm{mg})$, thickness between 6.4 and $6.6 \mathrm{~mm}$ $(6.5 \pm 0.1 \mathrm{~mm})$, hardness ranging between 5.0 and $6.5 \mathrm{~kg} / \mathrm{cm}^{2}$, and friability ranging between 0.35 and $0.71 \% \mathrm{w} / \mathrm{w}$. Marginal variation in tablet hardness and friability could be attributed only to the random causes, but not to the matrix composition. Also, the absence of any significant inter- and intra-batch variability in tablet hardness, friability, and thickness ruled out plausibility of any change in compression pressure and consequently the drug dissolution behavior. The

Table V. ANOVA Table Indicating Statistical Parameters for the CQAs of Gastroretentive Floating-Bioadhesive Tablets of Cefuroxime Axetil

\begin{tabular}{|c|c|c|c|c|c|c|}
\hline \multirow[t]{2}{*}{ CQAs } & \multicolumn{6}{|c|}{ ANOVA parameters } \\
\hline & Source & SS & Df & MSS & $F$ value & $p$ value \\
\hline \multirow[t]{5}{*}{$B S(\mathrm{~g})$} & Model & 749.48 & 7 & 107.07 & 8.52 & 0.0157 \\
\hline & Residual & 62.81 & 5 & 12.56 & - & - \\
\hline & Lack of fit & 23.24 & 1 & 23.24 & $2.35^{*}$ & 0.2001 \\
\hline & Pure error & 39.57 & 4 & 9.89 & - & - \\
\hline & Corr Total & 812.29 & 12 & - & - & - \\
\hline \multirow[t]{5}{*}{$T_{60 \%}(\mathrm{~h})$} & Model & 460.37 & 9 & 51.15 & 45.36 & 0.0001 \\
\hline & Residual & 7.89 & 7 & 1.13 & - & - \\
\hline & Lack of fit & 2.84 & 3 & 0.95 & $0.75^{*}$ & 0.5760 \\
\hline & Pure error & 5.05 & 4 & 1.26 & - & - \\
\hline & Corr Total & 468.26 & 16 & - & - & - \\
\hline \multirow[t]{5}{*}{$Q_{18 h}(\%)$} & Model & 1233.91 & 7 & 176.27 & 15.93 & 0.003 \\
\hline & Residual & 55.31 & 5 & 11.06 & - & - \\
\hline & Lack of fit & 28.69 & 1 & 28.69 & $4.31 *$ & 0.1065 \\
\hline & Pure error & 26.62 & 4 & 6.65 & - & - \\
\hline & Corr Total & $1289 . .22$ & 12 & - & - & - \\
\hline \multirow[t]{5}{*}{$n$} & Model & 2717.65 & 9 & 301.96 & 39.29 & 0.0001 \\
\hline & Residual & 53.80 & 7 & 7.69 & - & - \\
\hline & Lack of fit & 8.60 & 3 & 2.87 & $0.25 *$ & 0.8556 \\
\hline & Pure error & 45.20 & 4 & 11.30 & - & - \\
\hline & Corr Total & 2771.45 & 16 & - & - & - \\
\hline
\end{tabular}


characterization studies confirmed the physical parameters of compressed floating-bioadhesive tablets within the permissible limits.

In Vitro Drug Release Studies. Table IV summarizes the dissolution parameters computed for the prepared floatingbioadhesive tablet as per the experimental design. As per the data, the values of $T_{60 \%}$ were markedly extended from 4.2 to $16.1 \mathrm{~h}$ with increasing the concentration of both the polymers, i.e., PEO 303 and HPMC K100 LV CR, from low to high levels, respectively. Similarly, the values of $Q_{18 \mathrm{~h}}$ decreased drastically with increase in the polymer content. Nearly, $33.8 \%$ of drug was retained in the matrix till $18 \mathrm{~h}$ at higher levels of both the polymers. This could be attributed to the formation of high viscosity gel layer around the tablet, which impedes the release of cefuroxime axetil and provides appreciable diminution in the extent of drug absorption $(28,29)$. The release exponent $(n)$ showed an increasing trend with increase in the concentration of both polymers with values ranging between 0.471 and 0.954 . Further, evaluation of the kinetic constants revealed relatively higher magnitude of $k_{1}$ versus $k_{2}$ clearly indicating the drug release predominantly by Fickian diffusion over polymer relaxation mechanism (27).

In Vitro Floating Studies. The evaluation of the buoyancy revealed floating time more than $12 \mathrm{~h}$ in all the prepared floating-bioadhesive tablet formulations. This revealed adequate floatation characteristics of the prepared formulations, which can be assigned owing to the presence of sodium bicarbonate responsible for releasing the carbon dioxide upon coming in contact with the acidic pH of SGF. The mechanism of carbon dioxide generation is well known for exhibiting floatation of the prepared formulation $(6,30)$.

Ex Vivo Bioadhesion Studies. Figure 3 portrays the ex vivo bioadhesion strength of the prepared floating-bioadhesive tablet formulations as per the experimental design. A distinct increase in the bioadhesive strength was observed with an increase in the concentration of PEO 303. This could be attributed to the gel forming nature, where PEO 303 tends to imbibe water quickly upon coming in contact with water to exhibit bioadhesion
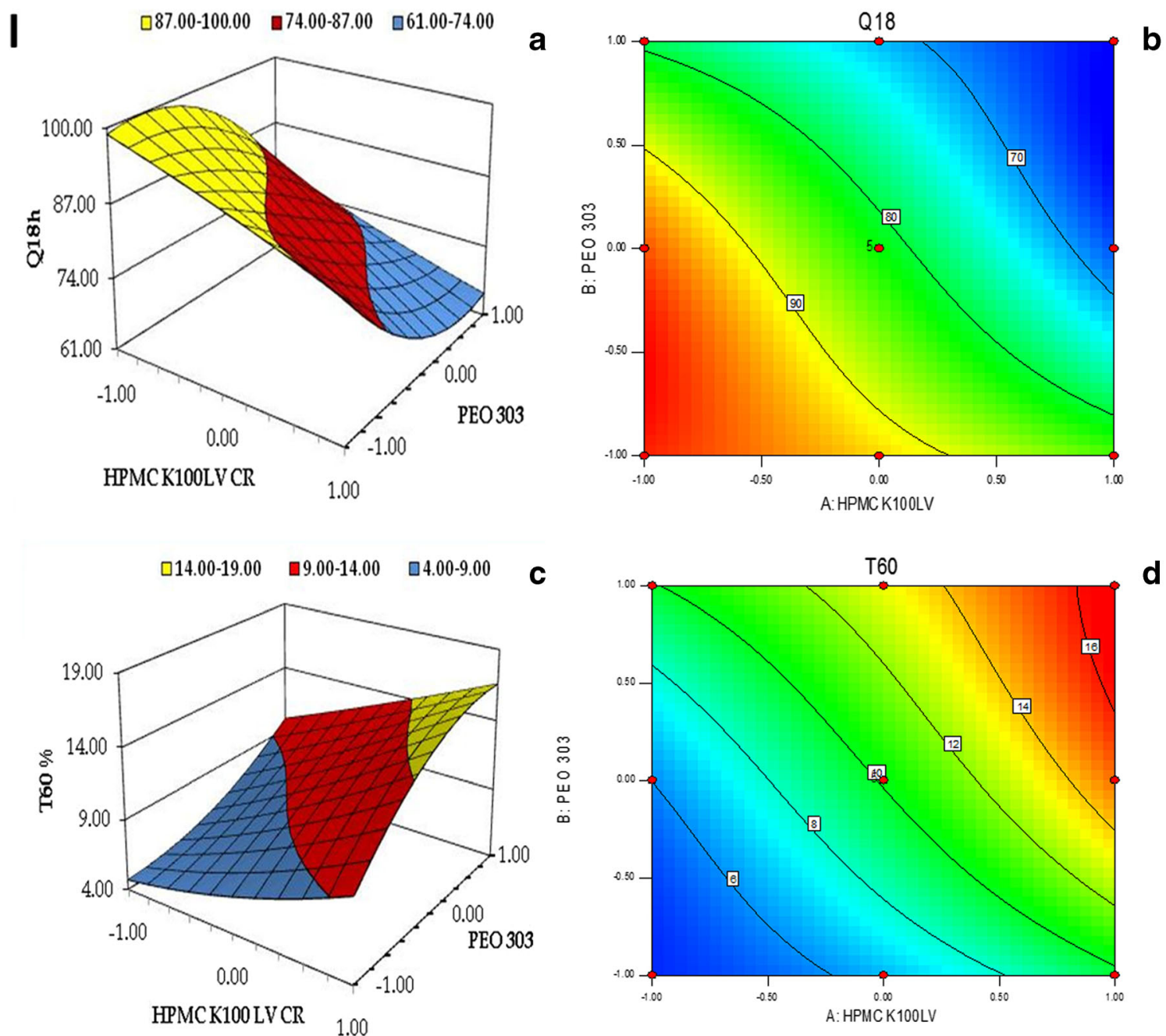

Fig. 4. I 3D-response surface plot and 2D-contour plot depicting the influence of PEO 303 and HPMC K100 LV CR on CQAs of GR floating-bioadhesive tablets, a-b $Q_{18 \mathrm{~h}}, \mathbf{c}-\mathbf{d} T_{60 \%} ;$ II 3D-response surface plot and 2D-contour plot depicting the influence of PEO 303 and HPMC K100 LV CR on CQAs of GR floating-bioadhesive tablets, $\mathbf{e}-\mathbf{f}$ BS, $\mathbf{g}-\mathbf{h}$ n 
II

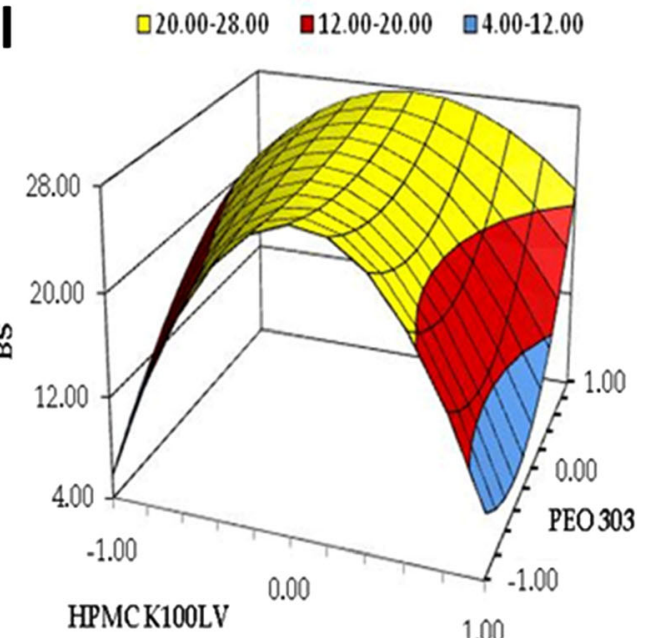

$\square 0.80 \cdot 1.00$

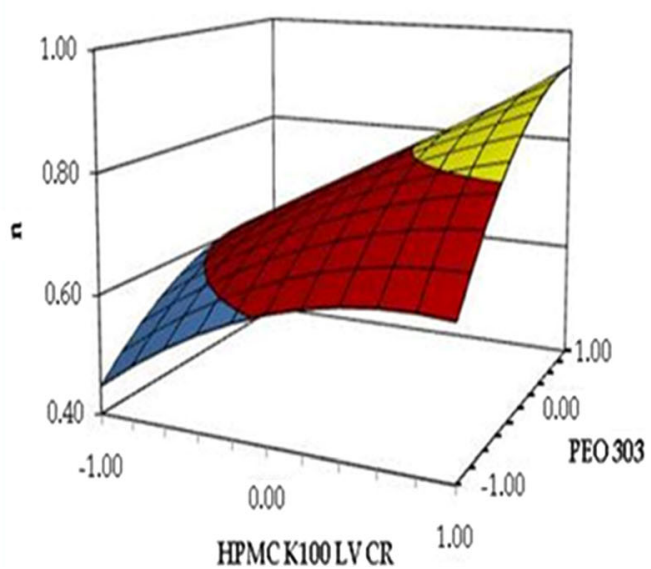

Fig. 4. (continued)

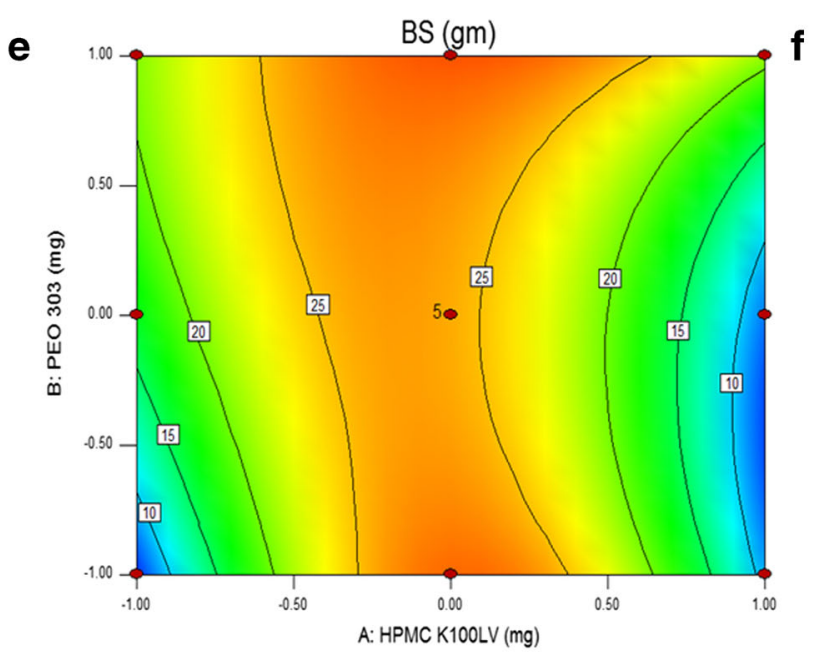

g

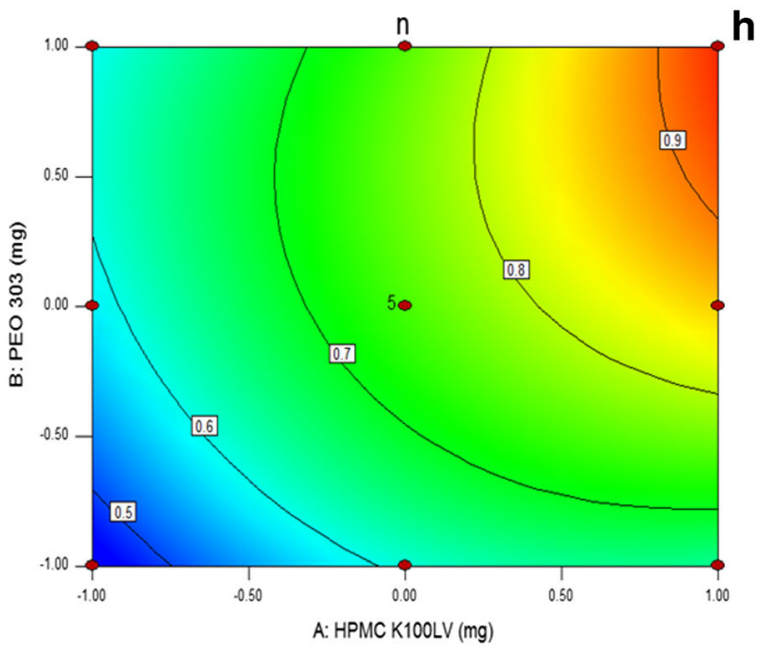

h characteristics (31). Besides, it has been reported that the linear chains of PEO form strong interaction with the gastric mucosa, thus responsible for bioadhesion of the dosage form with the gastric epithelial cell lining (32). The influence of HPMC K100 LV $\mathrm{CR}$, however, was found to be less prominent as compared to the PEO 303 on the bioadhesion strength. However, the bioadhesion characteristics of HPMC K100 LV CR can be attributed owing to its swellable nature by polymer relaxation mechanism, which helps in attachment of the dosage form with the gastric mucosa with the help of entanglement of the polymer chains with mucin chains (33). Overall, the studies revealed maximum bioadhesion strength of the prepared formulation at higher levels of PEO 303 and intermediate levels of HPMC K100 LV CR, where both interact synergistically for exhibiting the optimal bioadhesion.

Optimization Data Analysis and Response Surface Mapping. Table V enlists the ANOVA parameters for each of the CQAs values as per the selected second-order quadratic polynomial model given in Eq. (3-6). All the polynomial equations distinctly revealed the prevalence of interactions among the studied CMAs on the CQAs. Further, the evaluation of the selected model using statistical parameters like,

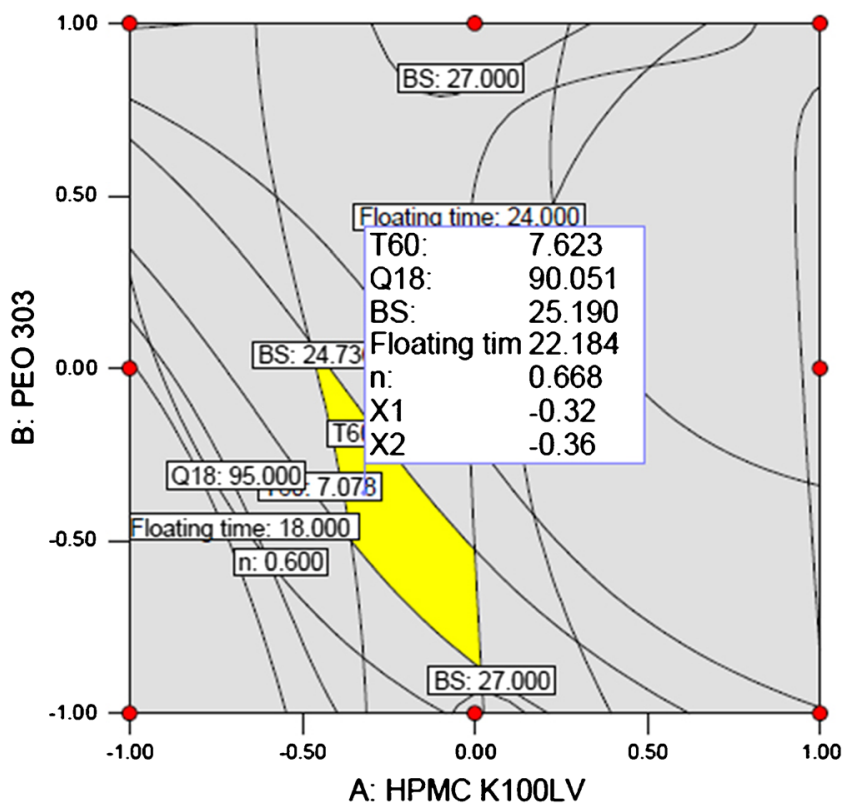

Fig. 5. Overlay plot depicting the location of optimized GR floatingbioadhesive tablet formulation 


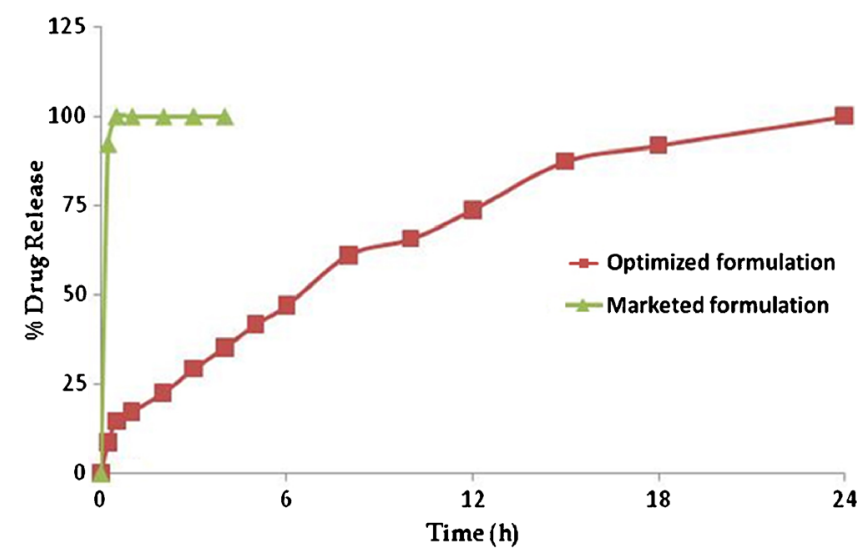

Fig. 6. Comparison of release performance of optimized floatingbioadhesive tablet formulation with marketed formulation (Pulmocef $^{\mathrm{TM}}$ )

high values of $R^{2}$ ranging between 0.9227 and $0.9571 \quad(p<0.005$ in each case), insignificant lack of fit, and low values of PRESS, ratifying excellent goodness of fit of the data.

$$
\begin{aligned}
B S= & 25.52-4.45 X_{1} \\
& +0.25 X_{2}-0.675 X_{1} X_{2}-13.37 X_{1}^{2}+1.92 X_{2}^{2} \\
& +6.42 X_{1}^{2} X_{2}+5.37 X_{1} X_{2}^{2} \\
Q_{18 h}= & 81.91-14.6 X_{1}-10.5 X_{2}+0.15 X_{1} X_{2} \\
& +0.11 X_{1}^{2}-0.18 X_{2}^{2}+0.65 X_{1}^{2} X_{2} \\
& +7.55 X_{1} X_{2}^{2}
\end{aligned}
$$

$$
\begin{aligned}
T_{60 \%}= & 10.13+4.5 X_{1}+3.3 X_{2}+0.435 X_{1} X_{2} \\
& +0.38 X_{1}^{2}-0.31 X_{2}^{2}-0.265 X_{1}^{2} X_{2}-1.585 X_{1}^{2} X_{2} \\
n= & 0.74+0.13 X_{1}+0.07 X_{1} \\
+ & 0.036 X_{2}-0.024 X_{1}^{2}-0.065 X_{1}^{2} \\
+ & 0.03 X_{1}^{2} X_{2}-0.002 X_{1}^{2} X_{2}
\end{aligned}
$$

Figure 4 (I-II) depicts the 3D-response surface plots for $Q_{18 \mathrm{~h}}, T_{60 \%}$, BS, and $n$. The response surface analysis furnished improved understanding of the interaction(s) among the CMAs and their impact on CQAs of the floatingbioadhesive tablets of cefuroxime axetil.

Figure $4 a-b(I)$, respectively, portrays the 3D-response surface plot and 2D-contour plot, indicating a sharp declining trend for $Q_{18 \mathrm{~h}}$ at all the levels of HPMC K100 LV $\mathrm{CR}$ and PEO 303. The influence of HPMC K100 LV CR in regulating the drug release was found to be more pronounced vis-à-vis PEO 303. This can be attributed to the swellable nature of HPMC K100 LV CR, which forms a glassy barrier on the dosage form plausibly owing to the water sorption mechanism and tend to regulate the drug release by Fickian diffusion mechanism (34). The evaluation of 2D-contour plots also revealed analogous observation among the studied polymers with moderate interactions prevailing between them, as is evident from the curved contour lines.

As depicted in Fig. 4c-d (I), a sharp escalating trend was observed in the values of $t_{60}$ with increase in the

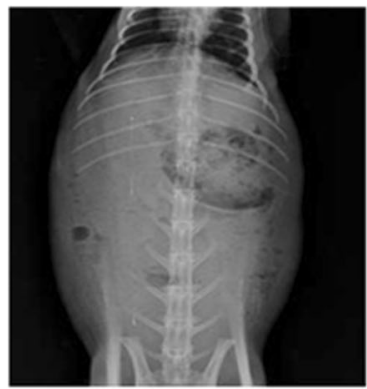

a

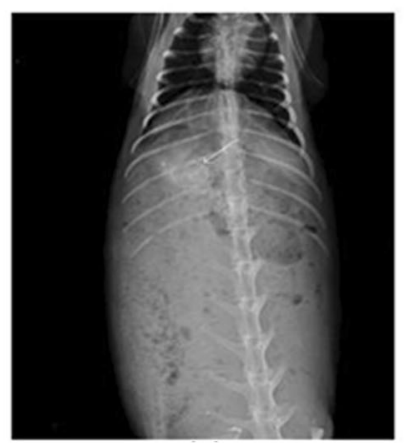

e

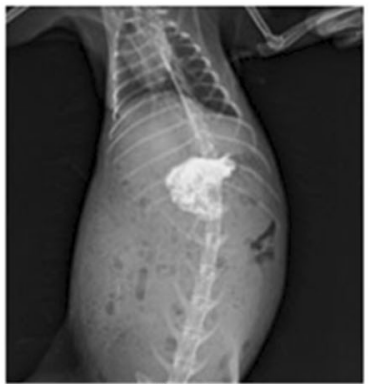

b

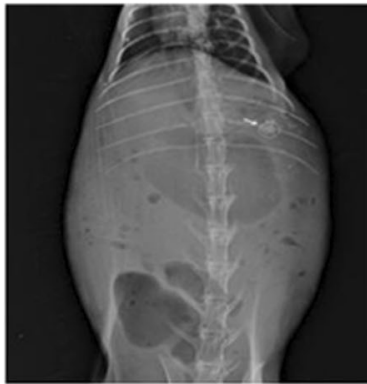

C

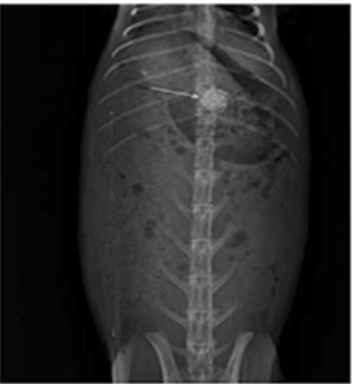

d

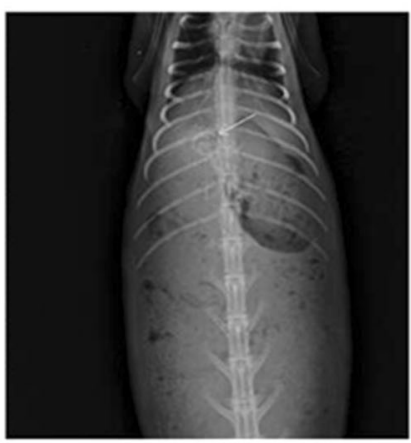

$\mathbf{f}$

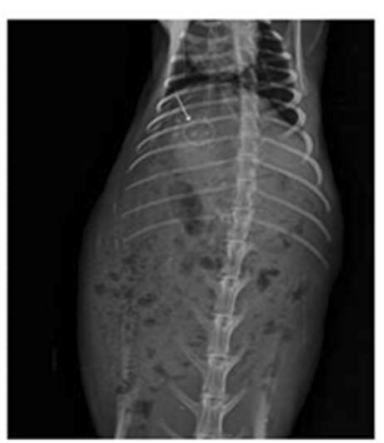

g

Fig. 7. X-ray images of the rabbit stomach a control animal, $\mathbf{b} 30 \mathrm{~min}$ after administration of marketed formulation, $\mathbf{c} 30 \mathrm{~min}$, d $2 \mathrm{~h}, \mathbf{e} 4 \mathrm{~h}, \mathbf{f} 6 \mathrm{~h}$, and $\mathbf{g} 12 \mathrm{~h}$ after administration of optimized floating-bioadhesive tablet formulation 


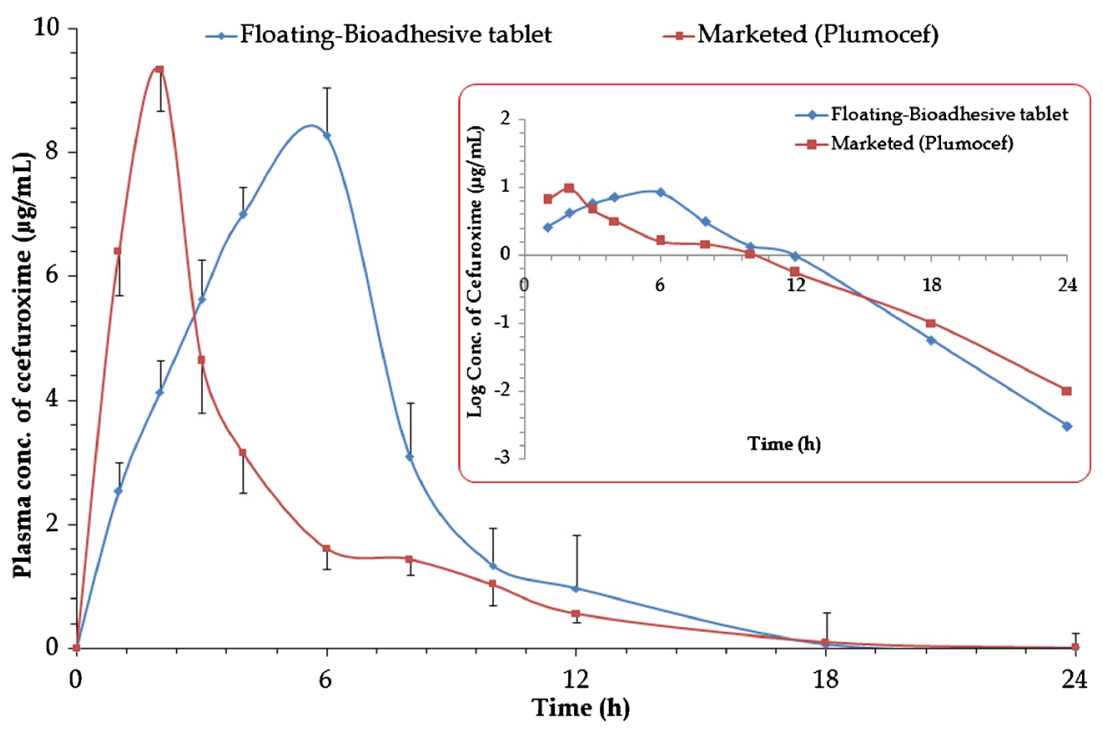

Fig. 8. Pharmacokinetic data indicating plasma concentration versus time profile from the optimized floating-bioadhesive tablet formulation and marketed formulation (Plumocef®).

The error bars indicate mean \pm 1 SEM

concentration of HPMC K100 LV CR and PEO 303. The higher values for $t_{60 \%}$ indicating controlled release profile of drug delivery were observed at higher levels of HPMC K100 LV CR. Owing to the swellable nature of HPMC K100 LV $\mathrm{CR}$, the extension in drug release rate was observed by diffusion mechanism as the major rate limiting factor. The analogous observations were also observed from the corresponding 2D-contour plot showing the linear trend for the contour lines.

Figure 4e-f (II) shows the 3D-response surface and 2Dcontour plot for bioadhesion strength demonstrating the curvilinear pattern for the studied factors, i.e., PEO 303 and HPMC K100 LV CR. The bioadhesion strength revealed a sharp rising trend up to the intermediate levels followed by a dip with increase in the concentration of HPMC. On the contrary, the values of BS increase almost linearly with increase in the amount of PEO at all the levels of HPMC. The results revealed combined influence of both the polymers in attributing the desired bioadhesion characteristics of the prepared formulation. The prevalence of high degree of interaction among the polymers was discerned from the 2D-contour plot depicting the curved contour lines.

The effect of HPMC K100 LV CR and PEO 303 on the release exponent ' $n$ ' is illustrated in Fig. 4II (G-H). The linear escalating values of the $n$ indicated the drug release by Fickian diffusion to the anomalous release mechanisms. Maximum values for $\mathrm{n}$ were observed at higher levels of both the polymers, indicating controlled release nature of the prepared formulations. This can be explained by the swellable and erodible nature of the selected polymers employed during the present studies (35). Unlike other CQAs, the ' $n$ ' was found to be regulated by both the polymers, thus confirming the combined role of them in assigning the typical release mechanism.

Search for Optimum Formulation and Validation of $Q b D$ Methodology. Selection of the optimum formulation was based on maximization of the CQAs viz. BS (i.e., essential for retention of the dosage form), $Q_{18 \mathrm{~h}}$ and $T_{60 \%}$ (i.e., indicative of drug release behavior), and $n$ (i.e., indicative of drug release mechanism) during feasibility and grid search methodology. Finally, the optimized formulation with desirability value close to unity was selected by numerical optimization technique, which contained PEO 303: $36.4 \mathrm{mg}$ and HPMC K100 LV CR: $67.2 \mathrm{mg}$, exhibiting BS of $25.19 \mathrm{~g}, T_{60 \%}$ of $7.623 \mathrm{~h}, Q_{18 \mathrm{~h}}$ of $90.051 \%$, and n of 0.668 . Figure 5 portrays the overlay plot depicting the design space region and optimized formulation.

Validation studies carried out by comparing the observed responses with the anticipated ones revealed the prediction error varied between -6.75 and $4.84 \%$ with overall mean \pm SD as $-0.21 \pm 6.54 \%$. Linear correlation plots

Table VI. Pharmacokinetic Parameters Obtained After Oral Administration of Various Formulations of Cefuroxime Axetil

PHARMACOKINETIC PARAMETERS

\begin{tabular}{llllll}
\hline $\begin{array}{l}T_{\max } \\
(\mathrm{h})\end{array}$ & $\begin{array}{l}C_{\max } \\
\left(\mu \mathrm{g} \mathrm{mL}^{-1}\right)\end{array}$ & $\begin{array}{l}\mathrm{AUC}_{24 \mathrm{~h}} \\
(\mu \mathrm{g} \\
\left.\mathrm{h} \mathrm{mL} \mathrm{mL}^{-1}\right)\end{array}$ & $\begin{array}{l}K_{\mathrm{a}} \\
\left(\mathrm{h}^{-1}\right)\end{array}$ & $\begin{array}{l}K \\
\left(\mathrm{~h}^{-1}\right)\end{array}$ & $\begin{array}{l}\mathrm{MRT} \\
\left(\mathrm{h}^{-1}\right)\end{array}$ \\
\hline $6.00 \pm 0.81$ & $8.28 \pm 0.78$ & $58.96 \pm 4.89$ & $0.41 \pm 0.42$ & $0.32 \pm 0.08$ & $5.63 \pm 0.23$ \\
$2.00 \pm 0.28$ & $9.34 \pm 1.63$ & $32.73 \pm 3.17$ & $0.89 \pm 0.39$ & $0.27 \pm 0.10$ & $4.39 \pm 0.19$ \\
\hline
\end{tabular}


drawn between the predicted and observed responses after forcing the line through the origin, also demonstrated high values of ' $r$ ' (0.934 to 0.986), indicating excellent goodness of fit in each case $(p<0.001)$ (data not shown). The corresponding residual plots also revealed quite regulated pattern with a relatively narrow, uniform, and random scatter around zero axes, indicating high degree of prognostic ability of the QbD approach.

Comparison of Drug Release Performance with Marketed Brand. Figure 6 portrays the comparative drug release profile for cefuroxime axetil from the conventional marketed immediate release tablet (Pulmocef $囚$ ) and optimized GR floatingbioadhesive tablet formulation. Strikingly different drug release profiles were observed for both the formulations. The marketed tablet showed almost complete drug release within 15 min owing to its immediate release nature, while the GR tablet showed $91.8 \%$ drug release in $18 \mathrm{~h}$ and nearly $100 \%$ drug release in $24 \mathrm{~h}$ ratifying its controlled release nature.

In Vitro Floating Studies. In vitro buoyancy studies confirmed that the optimized formulation showed instantaneous onset of floating behavior up to $22 \mathrm{~h}$ with zero lag time. This could be attributed to the effervescent nature of the prepared formulation owing to the presence of sodium bicarbonate, which upon contact with the acidic environment of gastric fluid tend to produce carbon dioxide gas $(14,36)$. In addition, the presence of HPMC K100 LV CR may also have contributed for assigning the floatation characteristics to the developed formulation. The floatation behavior confirmed enhanced gastroretention nature of the developed formulation.

In Vivo X-ray Imaging Studies. Figure 7 depicts the X-ray images of empty stomach of rabbit before and after peroral administration with the optimized floating-bioadhesive tablet of cefuroxime axetil. These images revealed prolonged residence time of the prepared tablet in the upper gastric region even after $12 \mathrm{~h}$ of administration. This confirmed gastroretentive nature of the prepared tablet formulation ostensibly owing to their floating-bioadhesive nature, which plausibly help in retaining the formulation for longer duration of time. As hypothesized, the floatation property tends to facilitate maintaining the buoyancy, while bioadhesive nature

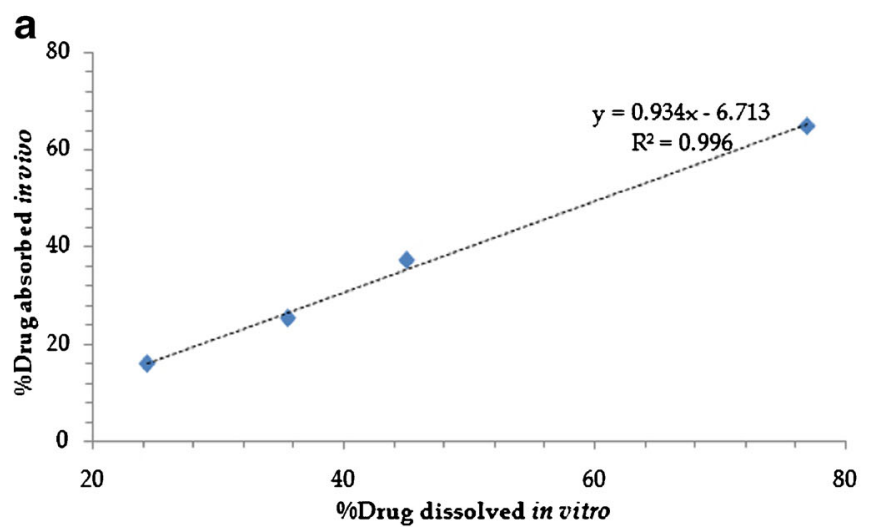

Fig. 9. Level A IVIVC for the optimized gastroretentive floating-bioadhesive tablet formulation (a) and marketed immediate release tablet formulation (b) prevents dislodgment of the formulation from the gastric region even by the action of forcible house-keeping waves $(6,14,37)$.

In Vivo Pharmacokinetic Studies. Figure 8 depicts the plasma concentration time profile of the drug $($ Mean \pm SD), as observed in rabbits, following administration of the gastroretentive floating-bioadhesive tablet and the marketed immediate release tablet (Plumocef®). Significantly different $(p<0.01$ to $p<0.001)$ values of individual plasma concentrations were observed almost at all the time points in both the formulations. The pharmacokinetic data were found to fit the best into the one-compartment open body-model (1-CBM) using WinNonlin software. Mono-linear decline characterizing 1-CBM kinetics is also evident from the log concentration time-profile of the drug from both the formulations (Fig. 8 inset). Statistical validity of the model fitness was ratified on the basis of low magnitudes of AIC, SC, SSR, and high values of R.

As portrayed in Table VI, the rate of drug absorption from the optimized floating-bioadhesive formulation was found to be quite slow and sustained $\left(T_{\max }=6.0 \mathrm{~h}\right.$; $\mathrm{MRT}=5.63 \mathrm{~h}$ ), as compared to the marketed immediate release formulation $\left(T_{\max }=2.0 \mathrm{~h}\right.$; MRT=4.39 h), indicating very significantly improved $(p<0.001)$ extension in the drug absorption profile. Likewise, the values of $K_{\mathrm{a}}$ from the optimized formulation were also found to be significantly lower than the marketed formulation ( $p<0.01$ each for each parameter). No appreciable difference, however, was found in the $C_{\max }$ values between the formulations. The extent of drug absorption, as revealed by the $\mathrm{AUC}_{24 \mathrm{~h}}$ values, was also found to be significantly higher from the optimized formulation than from the marketed formulation (i.e., 1.78-fold; $p<0.001$ ). Such enhancement in the bioavailable fraction is in consonance with several of previous reports on GR formulations $(1,8,38,39)$. Overall, the studies construe appreciable extension in drug absorption profile when formulated as floating-bioadhesive tablets, ostensibly owing to the increase in gastric residence time by virtue of its floatation and bioadhesion characteristics.

In Vitro/In Vivo Correlation (IVIVC). Level A IVIVC was attempted between the \%drug absorbed in vivo with the $\%$ drug dissolved in vitro at the corresponding time points. Figure 9a, b portrays the level A curves for the optimized gastroretentive floating-bioadhesive tablet formulation and

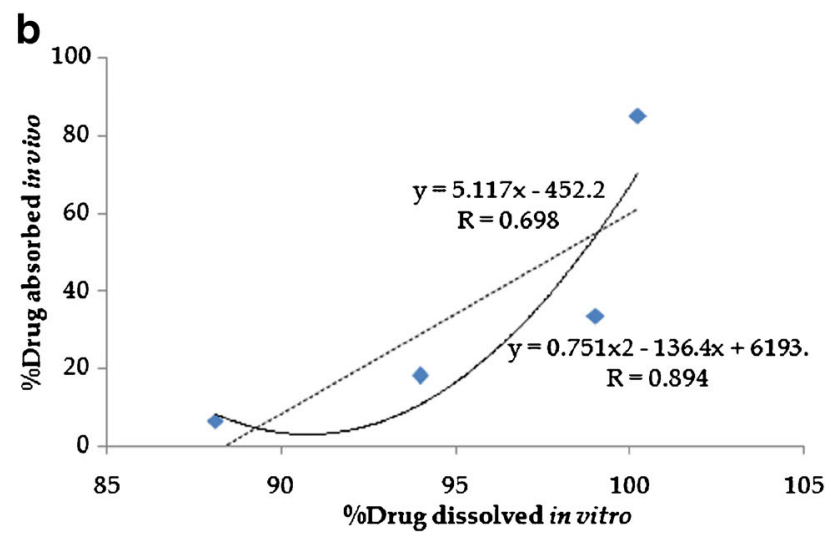


the marketed immediate release tablet formulation, respectively. Much more linearity of the IVIVC curve ( $r=0.996$; $p<0.001)$ was observed for the optimized gastroretentive formulation than for the marketed formulation $(r=0.698 ; p<0.01)$. The results confirmed the prevalence of IVIVC in the prepared gastroretentive formulation, as drug release was able to maintain a linear pace with the in vitro dissolution construing the in vivo drug absorption (16). The latter curve, however, exhibited significantly improved fitting with quadratic model demonstrating the prevalence of nonlinearity $(r=0.894$; $p<0.01$ ). The prevalence of such nonlinear pattern is in accordance with the literature studies reported for fast release formulations $(1,40)$. Besides exploring the magnitudinal relationship between the in vitro and in vivo data, the establishment of IVIVC also ratifies the apt selection of in vitro dissolution conditions like, dissolution apparatus, media composition, and time-points for predicting the in vivo pharmacokinetic performance $(8,41)$.

\section{CONCLUSIONS}

The present studies successfully vouch the use of rational QbD-based approach for the development of optimized floating-bioadhesive tablet formulation of cefuroxime axetil employing a simple and cost-effective method for improving the gastric residence time of the dosage form and accomplishing site-specific drug delivery. Preliminary formulation development along with FTIR and PXRD studies facilitated identification of the suitable polymer blends and their levels for formulation development. The optimized formulation exhibited excellent in vitro floating and desired drug release profile for prolonged periods of time, which was further confirmed by higher residence time of the prepared tablets during in vivo imaging studies in rabbits. Further, the in vivo pharmacokinetic studies in rabbits also indicated significant extension of drug absorption rate along with improved oral bioavailability vis-à-vis the marketed formulation. The correlation between in vivo pharmacokinetic parameters (i.e., drug absorbed) with the in vitro dissolution parameters (\%drug dissolved) also construed excellent degree of correlation between them. The promising outcomes from the current studies can also be extrapolated for accomplishing the controlled release profile of drug delivery for once-in-a day administration.

\section{ACKNOWLEDGMENTS}

The authors acknowledge the DST-FIST lab, UIPS, Panjab University, Chandigarh for providing, XRD, DSC, FTIR, and HPLC facilities. The authors are thankful to M/s Ranbaxy Laboratories Ltd, Gurgaon, India for providing the gift sample of Cefuroxime axetil and cefuroxime acid; Dr Amit Mittal, Head Department of Radiology, MMU, Mullana, Ambala for $\mathrm{X}$-ray imaging facility. Also the corresponding author of the manuscript Professor Bhupinder Singh, gratefully acknowledges the generosity of M/s Stat-Ease Inc., Minneapolis, USA for providing one perpetual license and 10-user annual licence of Design Expert ${ }^{\circledR}$ software, version 9.0, while conferring upon him the "Stat-Ease QbD Performance Award 2014" and "Premier Academic Status" for his unparalleled contribution in the area of QbD-based pharmaceutical research work.

\section{COMPLIANCE WITH ETHICAL STANDARDS}

Conflict of Interest. The authors declare no conflict of interest in this work.

\section{REFERENCES}

1. Singh B, Garg B, Chaturvedi SC, Arora S, Mandsaurwale R, Kapil R. Formulation development of gastroretentive tablets of lamivudine using the floating-bioadhesive potential of optimized polymer blends. J Pharm Pharmacol. 2012;64(5):654-69.

2. Gupta H, Bhandari D, Sharma A. Recent trends in oral drug delivery: a review. Recent Pat Drug Deliv Formul. 2009;3(2):16273.

3. Streubel A, Siepmann J, Bodmeier R. Drug delivery to the upper small intestine window using gastroretentive technologies. Curr Opin Pharmacol. 2006;6(5):501-8.

4. Pahwa R, Singh M, Kumar V, Kohli K. Recent advances and patent perspectives in gastroretentive technology. Recent Pat Drug Deliv Formul. 2012;6(3):278-90.

5. Kotreka UK, Adeyeye MC. Gastroretentive floating drugdelivery systems: a critical review. Crit Rev Ther Drug Carrier Syst. 2011;28(1):47-99.

6. Singh S, Singh J, Muthu MS, Balasubramaniam J, Mishra B. Gastroretentive drug delivery system of metoclopramide hydrochloride: formulation and in vitro evaluation. Curr Drug Deliv. 2007;4(4):269-75.

7. Eberle VA, Schoelkopf J, Gane PA, Alles R, Huwyler J, Puchkov $\mathrm{M}$. Floating gastroretentive drug delivery systems: comparison of experimental and simulated dissolution profiles and floatation behavior. Eur J Pharm Sci. 2014;58:34-43.

8. Kapil R, Dhawan S, Singh B, Garg B, Singh B. Systematic formulation development of once-a-day gastroretentive controlled release tablets of rivastigmine using optimized polymer blends. J Drug Del Sci Tech. 2012;22(6):511-21.

9. Scott LJ, Ormrod D, Goa KL. Cefuroxime axetil: an updated review of its use in the management of bacterial infections. Drugs. 2001;61(10):1455-500.

10. Ginsburg CM, McCracken Jr GH, Petruska M, Olson K. Pharmacokinetics and bactericidal activity of cefuroxime axetil. Antimicrob Agents Chemother. 1985;28(4):504-7.

11. Kaza M, Les A, Serafin-Byczak K, Ksycinska H, Rudzki PJ, Gutkowskpi P, et al. Bioequivalence study of $500 \mathrm{mg}$ cefuroxime axetil film-coated tablets in healthy volunteers. Acta Pol Pharm. 2012;69(6):1356-63.

12. Ruiz-Carretero P, Merino-Sanjuan M, Nacher A, Casabo VG. Pharmacokinetic models for the saturable absorption of cefuroxime axetil and saturable elimination of cefuroxime. Eur J Pharm Sci. 2004;21(2-3):217-23.

13. Patel VF, Patel NM. Intragastric floating drug delivery system of cefuroxime axetil: in vitro evaluation. AAPS PharmSciTech. 2006;7(1), E17.

14. Rao GK, Mandapalli PK, Manthri R, Reddy VP. Development and in vivo evaluation of gastroretentive delivery systems for cefuroxime axetil. Saudi Pharm J. 2012;21(1):53-9.

15. Nagar M, Yadav AV. Chitosan-based intragastric delivery of cefuroxime axetil: development and in-vitro evaluation of mucoadhesive approach. Artif Cells Blood Substit Immobil Biotechnol. 2012;40(6):406-18.

16. Bomma R, Veerabrahma K. Development of gastroretentive drug delivery system for cefuroxime axetil: in vitro and in vivo evaluation in human volunteers. Pharm Dev Technol. 2012;18(5):1230-7.

17. Menjoge AR, Kulkarni MG. Designing a self-associated cationic polymer for enhanced compatibility, palatability, and gastric release of cefuroxime axetil. Biomacromolecules. 2007;8(2):532-42.

18. Singh B, Pahuja S, Kapil R, Ahuja N. Formulation development of oral controlled release tablets of hydralazine: optimization of drug release and bioadhesive characteristics. Acta Pharm. 2009;59(1):1-13. 
19. Singh B, Raza K, Beg S. Developing "optimized" drug products employing "Designed" experiments. Chem Ind Digest. 2013;6:706.

20. Singh B, Kumar R, Ahuja N. Optimizing drug delivery systems using systematic "design of experiments." Part I: fundamental aspects. Crit Rev Ther Drug Carrier Syst. 2005;22(1):27-105.

21. Singh B, Dahiya M, Saharan V, Ahuja N. Optimizing drug delivery systems using systematic "design of experiments." Part II: retrospect and prospects. Crit Rev Ther Drug Carrier Syst. 2005;22(3):215-94.

22. Singh B, Kapil R, Nandi M, Ahuja N. Developing oral drug delivery systems using formulation by design: vital precepts, retrospect and prospects. Expert Opin Drug Deliv. 2011;8(10):1341-60.

23. Yu LX, Amidon G, Khan MA, Hoag SW, Polli J, Raju GK, et al. Understanding pharmaceutical quality by design. AAPS J. 2014;16(4):771-83.

24. Lionberger RA, Lee SL, Lee L, Raw A, Yu LX. Quality by design: concepts for ANDAs. AAPS J. 2008;10(2):268-76.

25. Singh B, Kaur T, Singh S. Correction of raw dissolution data for loss of drug during sampling. Indian J Pharm Sci. 1997;59:196-9.

26. Singh B, Singh S. A comprehensive computer program for study of drug release kinetics from compressed matrices. Indian $\mathbf{J}$ Pharm Sci. 1998;60:313-6.

27. Costa P, Lobo JMS. Modeling and comparison of dissolution profiles. Eur J Pharm Sci. 2001;13:123-33.

28. Reza MS, Quadir MA, Haider SS. Comparative evaluation of plastic, hydrophobic and hydrophilic polymers as matrices for controlled-release drug delivery. J Pharm Pharm Sci. 2003;6(2):282-91.

29. Singh B, Chakkal SK, Ahuja N. Formulation and optimization of controlled release mucoadhesive tablets of atenolol using response surface methodology. AAPS PharmSciTech. 2006;7(1), E3.

30. Singh B, Kaur A, Dhiman S, Garg B, Khurana RK, Beg S. QbDenabled development of novel stimuli-responsive gastroretentive systems of acyclovir for improved patient compliance and biopharmaceutical performance. AAPS PharmSciTech. 2015. doi:10.1208/s12249-015-0367-0.
31. Mahalingam R, Jasti B, Birudaraj R, Stefanidis D, Killion R, Alfredson $\mathrm{T}$, et al. Evaluation of polyethylene oxide compacts as gastroretentive delivery systems. AAPS PharmSciTech. 2009;10(1):98-103.

32. Patel DJ, Patel JK. Mucoadhesive effect of polyethyleneoxide on famotidine nanosuspension prepared by solvent evaporation method. Int J Pharm Pharm Sci. 2010;2(2):122-7.

33. Hiremath PS, Saha RN. Controlled release hydrophilic matrix tablet formulations of isoniazid: design and in vitro studies. AAPS PharmSciTech. 2008;9(4):1171-8.

34. Ravi PR, Ganga S, Saha RN. Design and study of lamivudine oral controlled release tablets. AAPS PharmSciTech. 2007;8(4):E101.

35. Perioli L, Pagano C. Gastroretentive inorganic-organic hybrids to improve class IV drug absorption. Int J Pharm. 2014;477(1-2):2131.

36. El-Zahaby SA, Kassem AA, El-Kamel AH. Design and evaluation of gastroretentive levofloxacin floating mini-tablets-incapsule system for eradication of Helicobacter pylori. Saudi Pharm J. 2014;22(6):570-9.

37. Bansal S, Beg S, Asthana A, Garg B, Asthana GS, Kapil R, et al. QbD-enabled systematic development of gastroretentive multiple-unit microballoons of itopride hydrochloride. Drug Deliv. 2014;28:1-15.

38. Singh B, Rani A, Babita, Ahuja N, Kapil R. Formulation optimization of hydrodynamically balanced oral controlled release bioadhesive tablets of tramadol hydrochloride. Sci Pharm. 2010;78(2):303-23.

39. Rhee YS, Park S, Lee TW, Park CW, Nam TY, Oh TO, et al. In Vitro/in vivo relationship of gabapentin from a sustained-release tablet formulation: a pharmacokinetic study in the beagle dog. Arch Pharm Res. 2008;31(7):911-7.

40. Emami J. In vitro-in vivo correlation: from theory to applications. J Pharm Pharm Sci. 2006;9(2):169-89.

41. Kapil R, Dhawan S, Beg S, Singh B. Buccoadhesive films for once-a-day administration of rivastigmine: systematic formulation development and pharmacokinetic evaluation. Drug Dev Ind Pharm. 2013;39(3):466-80. 